\title{
Signo de la punta del iceberg
}

\section{The Tip of the Iceberg Sign}

\author{
María Lorena Juana ${ }^{1}$ Jimena Mariano ${ }^{1} \quad$ Luciana Pipastrelli $^{1}$ \\ ${ }^{1}$ CIMED Alta Complejidad, Calle 5 N416, La Plata, Buenos Aires, \\ Argentina \\ Address for correspondence María Lorena Juana, Calle 74 N¹90, La \\ Plata, Buenos Aires, Argentina (e-mail: mlorenajuana@gmail.com).
}

Rev Argent Radiol 2019;83:87-88.

\section{Introducción}

El signo de la punta del iceberg describe el hallazgo ecográfico del teratoma ovárico maduro en una de sus formas más características de presentación. Fue denominado así por Guttman $\mathrm{PH} \mathrm{Jr}^{1}$ en el año 1977, por su similitud a la punta de un iceberg. Ese signo ecográfico se corresponde con una imagen ecogénica con gran sombra acústica posterior de localización ovárica, que condiciona la imposibilidad de visualizar las estructuras o elementos localizados por detrás de la misma y que corresponde a la interfase de los diferentes componentes del tumor, tales como grasa o pelos (-Fig. 1). ${ }^{2}$

\section{Características y hallazgos imagenológicos}

La ecografía es considerada el método de elección y la herramienta fundamental para la detección y evaluación inicial de las masas ováricas, debido a su bajo costo y a su indicación de rutina en el control ginecológico. Además, en manos expertas resulta altamente eficiente en el diagnóstico del teratoma. ${ }^{3}$ La tomografía computada (TC) y la resonancia magnética (RM), pueden demostrar con gran exactitud los componentes del teratoma, entre ellos grasa, calcio y pelos. 4

El teratoma maduro, también llamado quiste dermoide, es el tumor benigno más frecuente, derivado de las células germinales del ovario. El $80 \%$ se presenta en mujeres en edad fértil y entre un $7 \%$ y un $25 \%$ son bilaterales. Presentan un crecimiento lento, por lo cual la mayoría resulta asintomático (60\%) y suele ser un hallazgo en ecografías ginecológicas de control o bien debutar con dolor abdominal (48\%), que puede ser agudo en caso de torsión o ruptura espontánea. La torsión (3,5\%) puede presentarse cuando el tumor alcanza un tamaño mayor a $10 \mathrm{~cm}^{4,5}$

El tumor dermoide es una lesión quística que contiene en su interior una masa amorfa formada por la combinación de

received

September 21, 2018

accepted

May 13, 2019
DOI https://doi.org/

10.1055/s-0039-1692436.

ISSN 1852-9992. tejidos maduros como pelos, piel, apéndices cutáneos y sus detritus, hueso, entre otros. Esos son los responsables de las distintas apariencias ecográficas en las que se presenta ese tumor, entre las cuales encontramos múltiples imágenes lineales ecogénicas flotando dentro del quiste. La denominada "malla dermoide" corresponde a pelos, la presencia de un nódulo mural ecogénico dentro del quiste es llamado "tapón dermoide" y contiene pelos u otros elementos sólidos, o bien un nivel líquido- líquido o grasalíquido. ${ }^{2,5,6}$

El signo de la punta del iceberg es un hallazgo ecográfico específico de teratoma maduro, y es el resultado de la combinación de grasa, calcio y pelos cuyas interfases generan una sombra acústica posterior característica que imposibilita la visualización de estructuras por debajo de la misma, en el contexto de una lesión quística generalmente de gran tamaño. Debido a eso, es posible detectar ese signo tanto en la exploración endocavitaria como suprapúbica (-Fig. 2). ${ }^{2}$ Muchas veces, su visualización se hace dificultosa debido a que sus componentes semejan estructuras adyacentes tales como la grasa pelviana o el gas intestinal. ${ }^{6}$

Asimismo, la detección de este signo característico permite hacer el diagnóstico diferencial y descartar otras causas de masas ováricas como abscesos, quistes hemorrágicos o endometriomas y su presencia disminuye las posibilidades de que se trate de una lesión maligna. ${ }^{2}$

\section{Conclusión}

Dado que la ecografía constituye el método de elección para el estudio de pacientes con sospecha de masas ováricas y también teniendo en cuenta que muchos de los teratomas se descubren de manera incidental en controles rutinarios, el reconocimiento del signo de la punta del iceberg resulta fundamental para el correcto diagnóstico del teratoma ovárico.
Copyright @ $\odot 2019$, Sociedad Argentina de Radiología. Publicado por Thieme Revinter Publicações Ltda., Rio de Janeiro, Brazil. Todos los derechos reservados.
License terms

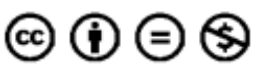




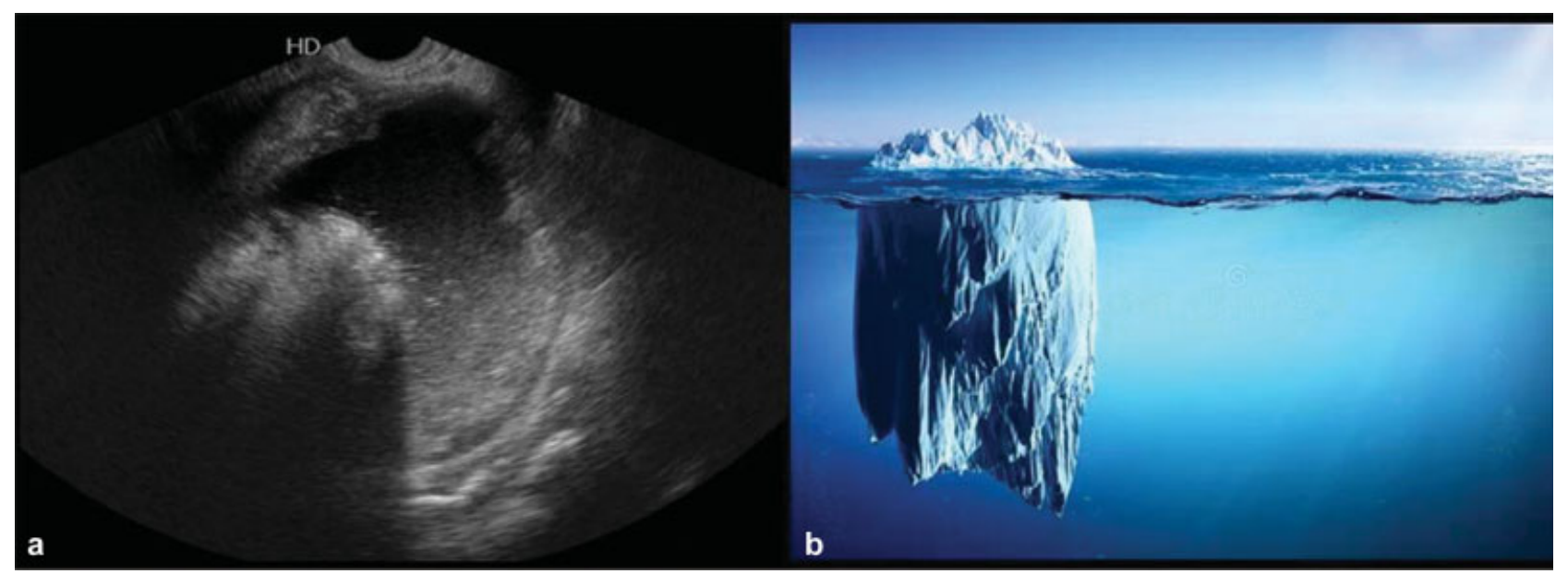

Fig. 1 (a) Imagen de ecografía ginecológica endovaginal, donde se observa una lesión quística en área anexial derecha que presenta en su interior una formación ecogénica con sombra posterior, conformando el signo de la punta del iceberg, compatible con teratoma. (b) Esquema comparativo de un iceberg.

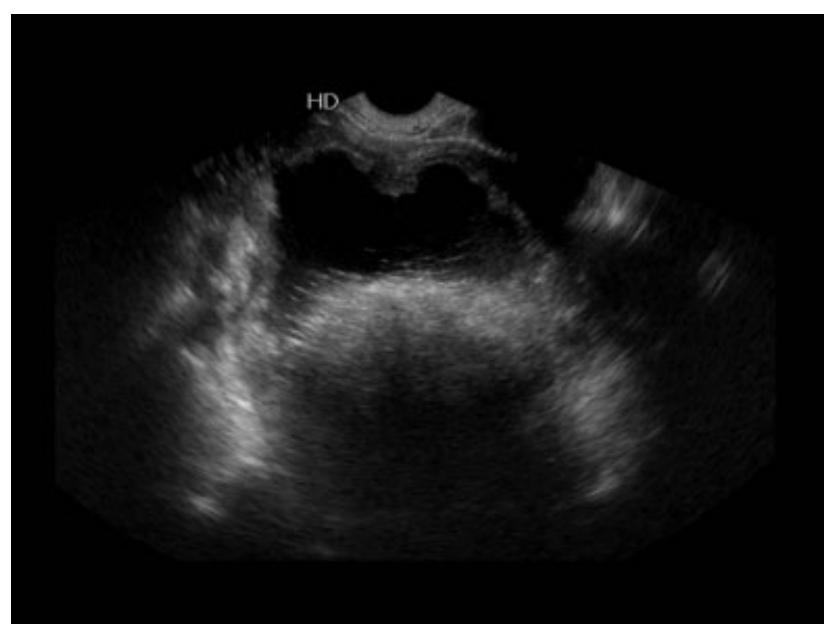

Fig. 2 Imagen de ecografía endovaginal, donde se observa una lesión quística en área anexial derecha con el signo de la punta del iceberg que impide la visualización de estructuras por debajo del mismo.

\section{Confidencialidad de los datos}

Los autores declaran que han seguido los protocolos de su centro de trabajo sobre la publicación de datos de pacientes y que todos los pacientes incluidos en el estudio han recibido información suficiente y han dado su consentimiento informado por escrito.

\section{Conflicto de intereses}

Los autores declaran no tener ningún conflicto de intereses.

\section{Bibliografía}

1 Guttman PH Jr. In search of the elusive benign cystic ovarian teratoma: application of the ultrasound "tip of the iceberg" sign. J Clin Ultrasound. 1977;5(06):403-406

2 Beller MJ. The "tip of the iceberg" sign. Radiology 1998;209(02): 395-396

3 Poggio GA, Mariano J, Gopar LA, Ucar ME. La ecografía primero: ¿Por qué, cómo y cuándo? Rev Argent Radiol 2017;81(03):192-203

4 Solís Alfonso L, Álvarez Padrón JF, Piñeira BM, Pérez Escriban J. Diagnóstico imagenológico de un teratoma gigante de ovario. Rev Cuba Med Mil 2011;40(02):182-188

5 Álvarez de la Rosa M, Padrón E, Hernández P, Trujillo JL. Teratoma quístico de ovario con concreciones sólidas. Rev Chil Obstet Ginecol 2006;71(04):263-266

6 Laing FC, Allison SJ. US of the ovary and adnexa: to worry or not to worry? Radiographics 2012;32(06):1621-1639, discussion 1640-1642 